\title{
Ill-being or well-being? Energising international business travellers
}

\author{
Lucy Rattrie \\ Department of Management, Work and Organization, University of Stirling, \\ Stirling, UK, and \\ Markus Kittler \\ Management Center Innsbruck, Innsbruck, Austria
}

Wellbeing of international business travellers

Received 9 February 2019 Revised 26 July 2019 Accepted 9 November 2019

\begin{abstract}
Purpose - The purpose of this qualitative study is to explore well-being experiences of international business travellers (IBTs) and contribute to our understanding of personal and job characteristics as antecedents of ill- or well-being.

Design/methodology/approach - The authors' insights are based on semi-structured in-depth interviews with 32 IBTs assigned to various destinations ranging from single-country travel to global operation. Participants in this study represent a range of traveller personas (regarding demographics, type of work, travel patterns). Thematic analysis is used to reveal new insights.

Findings - The authors' analysis revealed trip-load (i.e. workload, control, organisational support) and intensity of travel (i.e. frequency, duration and quality) as job characteristics that sit on an energy stimulation continuum, driving work-related outcomes such as stress and burnout or health and well-being. Energy draining and boosting processes are moderated by cognitive flexibility and behavioural characteristics.

Practical implications - Findings represent a framework for managing IBT well-being via adjustments in job and travel characteristics, plus guidance for training and development to help IBTs self-manage.

Originality/value - The insights within this paper contribute to the conversation around how to enhance well-being for IBTs and frequent flyers. The study intends to offer direction as to which specific job, psychological and behavioural characteristics to focus on, introducing a novel framework for understanding and avoiding serious consequences associated with international mobility such as increased stress, burnout and ill-health.
\end{abstract}

Keywords Well-being, Energy, Recovery, Cognitive flexibility, Frequent flyer, International business traveller

Paper type Research paper

\section{Introduction}

Managing an internationally mobile workforce successfully (i.e. in human resources, travel management and global mobility) is associated with effective employees, workforces and organisations (Sparrow, 2012). In an increasingly internationalised business world, there currently is a rising demand in people working abroad (Brookfield Global Relocation Services, 2016), posing challenges to both the international organisations and the individuals deployed outside their home countries. In addition to traditional forms of expatriation (e.g. McNulty and Brewster, 2017 for an overview) newer forms of international work yield further complexity. More recently, professionals whose work environments are characterised by a

(C) Lucy Rattrie and Markus Kitter. Published by Emerald Group Publishing Limited. This article is published under the Creative Commons Attribution (CC BY 4.0) licence. Anyone may reproduce, distribute, translate and create derivative works of this article (for both commercial and non-commercial purposes), subject to full attribution to the original publication and authors. The full terms of this licence may be seen at http://creativecommons.org/licences/by/4.0/legalcode.

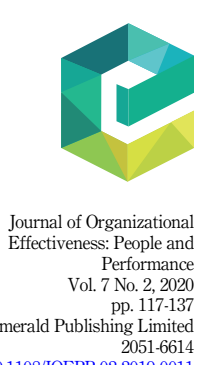

DOI 10.1108/JOEPP-02-2019-0011 
JOEPP
7,2

118

need for frequent flying, such as international business travellers (IBTs), attracted interest from scholars and practitioners.

Making use of the IBT option for international deployment requires a good understanding of the particular job characteristic with IBTs being particularly prone to developing physical and psychological illness (Cardoso and Jordão, 2017; Cohen et al., 2017; Mäkelä and Kinnunen, 2018; Rundle et al., 2018). Research also suggests that working as an IBT often is accompanied by a worsened social life, community and family relationships (Cohen and Gössling, 2015), loneliness and isolation (Gustafson, 2014), work-life balance issues (Niessen et al., 2018) and degraded quality time at home due to needing to recover and prepare for the next trip (Black and Jamieson, 2007). These risks are also increasingly highlighted in more practitioner-oriented outlets (e.g. see Cohen et al., 2017; GBTA, 2017; Harrop and Robertson, 2010). The challenges IBTs are exposed to are believed to have an effect on organisational success, for example, through "sickness-absence, productivity, customer satisfaction, employee turnover and retention" (Harrop and Robertson, 2010, p. 2).

Despite increasing academic discourse around these potential risks, literature also reports (albeit to a lesser degree) positive IBT outcomes, largely connected to career and lifestyle factors, such as enhanced professional status, broader appreciation of different cultures, cosmopolitan identities, prestige and glamour, open-mindedness and more vigour (a dimension of engagement; Beaverstock et al., 2009; Gustafson, 2014; Westman et al., 2009a). It therefore appears that whilst international travel exacerbates physical, psychological and life risks, various protective or motivational factors may simultaneously be in place that help employees achieve well-being despite additional challenges from travel; a viewpoint reflected in media (e.g. Eyears, 2018; Gill, 2016; Rattrie, 2017, 2018; Rundle, 2018) and academic reports (Collings et al., 2007; Gustafson, 2014; Jensen and Knudsen, 2017; Meyskens et al., 2009; Welch et al., 2007). Insights on well-being and its antecedents for the case of IBTs hence appear both practically and theoretically relevant.

Evidence supporting the role of well-being in employee and organisational success factors is increasing (Miller, 2016). The "happy worker-productive worker" belief, whereby employees who are happy are more productive and vice versa and act as a driver of organisational performance (Wright and Cropanzano, 2000) has found support in the extant literature. For example, Nielsen et al. (2017) show clear support for the importance of wellbeing in their systematic review and meta-analysis. This relationship appears to be emphasised for IBTs, making well-informed travel management strategies and policies extremely important, alongside appropriate interventions for IBT well-being management (Harrop and Robertson, 2010). As noted by Nielsen et al. (2017), organisations need to know how to ensure such happy and productive workers if they are to be successful, a situation that also applies to IBTs. However, as noted by Welch et al. (2007, p. 3), "despite the increasing need for, and use of, such people, there is a dearth of research on the IBT ... Why is there such neglect of what can be described as a strategic group of employees?" Similarly, Shaffer et al. (2012) suggest that it remains largely unclear how to manage IBT work experiences, leading to calls for imminent research and relevant theoretical frameworks. This is also in line with Nielsen and Miraglia (2017), who suggest a need for more specificity within organisational interventions considering what works for whom, under which circumstances, using tailored measures for achieving desired outcomes in well-being.

This paper focusses on improving understanding on how to manage IBTs and ensure their well-being. Thus, we aim to firstly explore IBT experiences to illustrate what may cause ill-being versus well-being. Secondly, we query whether the job demands-resources (JD-R) theory (Bakker and Demerouti, 2017) is a useful frame for the IBT context or whether a new model that builds upon earlier theory is needed. Our efforts are made with the intention of providing a fertile research ground in this cross-disciplinary field, an intention in line with prominent academics to "cross-fertilise academic debates, forging points of common 
understanding and informing respective disciplines of knowledge that can co-opted an applied to new settings" (Sparrow and Cooper, 2014, p. 3). Adopting guidance from Whetten (1989) and considering the axis from Colquitt and Zapata-Phelan (2007), a contribution in this manner is representative of theory building and offers "strategic (and policy) thinking ... with findings that can provide guidance on the best way forward" (Sparrow and Cooper, 2014, p. 3).
Wellbeing of international business travellers

\section{The growth of international business travel}

IBTs are a related concept to business expatriates (McNulty and Brewster, 2017). They can be defined as "employees who take multiple short international business trips to various locations without accompanying family members" (Shaffer et al., 2012) and are considered an essential component of business life (Welch et al., 2007). They usually tend to be higher-level executives and leaders, operating across dual or multiple work contexts for short periods, residing in temporary accommodation (Collings et al., 2007; Mayerhofer et al., 2004; Meyskens et al., 2009; Shaffer et al., 2012). Duration and frequency of trips can vary ranging from one day in a neighbouring country to one month spent as a "road warrior" moving from country to country. Depending on the regularity of travel, location or structure, they are also known as international commuters, flex-patriates, frequent flyers, globetrotters or road warriors (Mayrhofer et al., 2012).

There exists an emerging portfolio of IBTs (see Boiler et al., 2017, for an industry overview and detailed account) who respond to volatile international markets, irregular or short-term tasks, face-to-face contact and within regions possessing efficient international transport systems, where flights, for example, are part of daily modern life. In the future IBTs may even play a greater role than traditional expatriates, particularly where knowledge acquisition and dissemination is concerned (Welch et al., 2007), establishing or closing overseas operations and flexibility in operations (Mayrhofer et al., 2012). As a result, the number of IBTs in operation are rapidly increasing due to their potentially future contribution for organisational success (Mäkelä et al., 2014). However, with little insight on their specific job demands and resources, recent research suggests that organisations should be able to understand the pressures under which IBTs operate in order to develop and maintain supportive HR practices (Mäkelä and Kinnunen, 2018).

While there is strong support and consensus in the literature that the IBT as a form of internationally mobile work is increasing, precise figures remain unclear. Mäkelä et al. (2017) argue that reasons for the absence of precision is due to many international organisations not providing formal mobility figures and that additional complexity is added when IBTs are sent abroad from a country in which they are non-citizens. While precise figures on the emergence of IBTs hence are not available, statistical data provides indications of growth: in 2017, business travel contributed a total of US $\$ 1.23$ trillion to the global economy; spending was forecast to grow by $7 \%$ in 2019; and it is expected that business travel will increase alongside globalisation (Statista, 2018b). The number of US domestic business trips rose from $461.1 \mathrm{~m}$ in 2008 to $458.9 \mathrm{~m}$ in 2016 and is forecast to reach $478.2 \mathrm{~m}$ by 2020 (Statista, 2018a).

\section{International business travel and well-being: towards a JD-R perspective}

The term "international business travel" often evokes images of luxury and glamour and research suggests development opportunity, broadening of horizons and social networks, plus benefits to being in a separate environment to the norm (DeFrank et al., 2000; Welch and Worm, 2006; Westman et al., 2008). However, frequently, the very nature of working internationally presents a challenging context involving travel to different geographical regions with various cultures to navigate, impact to social life from short notice for 
$\mathrm{JOEPP}_{7,2}$

travel, pressures stemming from family responsibilities (especially for females), plus additional strain experienced due to pre-, during or post-trip workload, planning or logistics (Collings et al., 2007; DeFrank et al., 2000; Mayrhofer et al., 2012; Welch et al., 2007; Westman et al., 2008).

Increasingly, researchers point towards a need to further understand working conditions unique to IBTs in order to avoid negative outcomes such as recognising a distinctive situation exacerbated by the very nature of travel (e.g. role conflict, role expectations, workload, safety concerns, isolation), high frequency or duration of trips, work-family conflict, lack of worklife balance, lack of recovery time and physical health issues (e.g. weight gain, sleep issues, lack of exercise) (see, e.g. Burkholder et al., 2010; Cohen and Gössling, 2015; Gustafson, 2016; Harrop and Robertson, 2010; Mayerhofer et al., 2004; Meyskens et al., 2009; Westman et al., 2009b). Even 20 years ago (e.g. see Striker et al., 1999), health insurance claims for IBTs were considerably higher than for non-business travellers, with claims for psychological stressrelated disorders carrying the strongest association with the act of travel itself - a figure we expect to have risen. In sum, it appears that whilst there are positive outcomes for employees who travel internationally, these are quite limited to career, networking and cultural exposure benefits and outweighed by negative outcomes related to physical, psychological, social and life factors.

A possible theoretical lens to address well-being and performance-related outcomes of IBTs might be found in the JD-R theory (Bakker and Demerouti, 2017). JD-R theory has become increasingly popular for managing well-being and performance outcomes, incorporating a blend of work and personal characteristics, with evidence supporting its use across various contexts and cultures (Rattrie et al., 2019). In a quantitative study with Finnish IBTs, Mäkelä and Kinnunen (2018) have already indicated that the JD-R logic can be used to examine the role of job demands and resources for work-related outcomes associated with IBTs. In a similar vein, Rattrie and Kittler (2014) submit that the flexibility and previous success of JD-R theory suggest that it may capture the IBT context quite well in its current form or allow for adjustments that incorporate processes and boundaries unique to the IBT context. This is indicated in the research illustrated earlier pointing at the unique work conditions and personal impact stemming from travel.

Whilst a number of well-being and performance theories exist, JD-R theory is felt particularly appropriate for the context of this study. JD-R theory builds upon earlier work such as the conservation of resources theory (Hobfoll, 2001), job demands-control theory (Karasek, 1979) and effort-reward imbalance (Siegrist, 1996). It incorporates and advances their core principles collectively, being applied to various organisational issues around strategy, programmes and policy, inspiring hundreds of empirical articles (Bakker and Demerouti, 2017; Schaufeli, 2017), including empirically with the IBT context (Mäkelä and Kinnunen, 2018) and as a review within the IBT context (Rattrie and Kittler, 2014).

Since its initial introduction (see Demerouti et al., 2001), the JD-R model has found substantial attention in the work and occupational psychology literature, spilled over into the business and management domain and is now acknowledged as a theory illustrating the links between working conditions, individual characteristics and well-being outcomes. JD-R theory highlights eight different processes inspired by the aforementioned earlier theories including: direct and interactive demand/resource to strain/motivation, with reversed causal and gain/ loss spiral processes. According to Bakker and Demerouti (2017), JD-R theory assumes that all types of work characteristics can be classified into either job demands or job resources. Each instigates health impairment (i.e. leading to strain symptoms, such as exhaustion, anxiety, health complaints or general ill-being) or motivational processes (i.e. leading to engagement, commitment, flourishing or well-being) with the health impairment pathway being shown to worsen job performance whilst the motivational pathway is shown to enhance job performance. 
Job demands (e.g. work pressure, emotionally demanding interactions) are typically defined as "those physical, psychological, social, or organizational aspects of the job that require sustained physical and/or psychological effort and are therefore associated with certain physiological and/or psychological costs". Job resources (e.g. autonomy, skill variety, performance feedback, growth opportunity) are defined as "those physical, psychological, social, or organizational aspects of the job that are functional in achieving work goals, reducing job demands and the associated physiological and psychological costs, or stimulate personal growth, learning and development" (Bakker and Demerouti, 2017, p. 2). Job demands are further broken down into two categories: hindrance job demands (e.g. role conflict, role overload, role ambiguity) and challenge job demands. Hindrance job demands are those work characteristics that create blockers or constraints that interfere with an employees' ability to achieve their goals (Cavanaugh et al., 2000). Challenge job demands (e.g. high workload, time pressure, responsibilities) are demands that take effort yet simultaneously promote personal growth and achievement (Podsakoff et al., 2007).

Within JD-R theory, job resources are discussed to buffer the impact of job demands on strain. In consequence, employees with substantial access to job resources will cope better with demands (Xanthopoulou et al., 2007; Bakker et al., 2010), and they particularly influence motivational processes when job demands are high, as this is when job resources are needed the most (Bakker and Demerouti, 2017). In a similar vein, personal resources, defined as "the beliefs people hold regarding how much control they have over their environment . . . and that they are capable to handle unforeseen events" (Bakker and Demerouti, 2017, p. 3), are also expected to buffer the negative impact of job (hindrance) demands and boost the positive impact of (challenge) demands.

More recently, evidence has emerged for causal and reversed causal effects over time, between job demands, resources and well-being and in particular the role of job crafting or self-undermining behaviours, both meaning that the individual has some control over the degree of outcomes in a negative or positive way. Regarding the motivational process, work engagement predicted personal initiative, which led to higher work engagement, which encouraged future job resources (Hakanen et al., 2008). Likewise, job resources predicted levels of self-efficacy, optimism and self-esteem (i.e. job resources) and work engagement, whilst engagement and personal resources also predicted job resources (Xanthopoulou et al., 2009). Central to that appears to be the individual's ability to use job crafting behaviours, creating a self-initiated "gain spiral" of resources. Originally introduced by Wrzesniewski and Dutton (2001), job crafting within the JD-R model refers to the proactive changes an employee makes to self-manage job demands, increase and utilise job and personal resources (Tims et al., 2012).

Regarding the health impairment process, it seems as employees become more exhausted or cynical, they create more job demands and vice versa (Bakker et al., 2000; Demerouti et al., 2004). This suggests that with stress or burnout present, more job demands will be created over time creating a loss spiral, thought to be a result of self-undermining behaviours, which refers to a "behaviour that creates obstacles that may undermine performance" (Bakker and Costa, 2014, p. 115).

Despite its success, shortcomings are present which suggest a need to offer a more international JD-R theory or an expanded or modified approach to the IBT context. For instance, a recent meta-analysis by Rattrie et al. (2019) suggests a moderating role of contextual factors such as culture and argues that more contextualised versions of JD-R theory might increase its relevance to practitioners. Yet the underlying JD-R logic would prevail. As noted by Bakker and Demerouti (2017), building on earlier theories in this way is a valuable scientific practice, and whilst the theory's flexibility has likely driven its success, more specificity for particular contexts would enhance quality of applicability and predictions towards achieving well-being and performance outcomes.
Wellbeing of international business travellers 
$\mathrm{JOEPP}_{7,2}$

Employing JD-R theory in the IBT context also challenges the previous demands and resources classifications. Job characteristics in the IBT context might additionally be more difficult to classify as either a demand or a resource (and therefore to see them as contributing to well-being or ill-being). JD-R theory assumes that a job characteristic is typically either a job demand or a job resource, for example, workload is typically a demand whilst support is typically a resource. However, curvilinear effects may be present influencing whether they act as demands (challenge or hindrance) or resources, for example, too little workload could be perceived more demanding than a higher amount of workload (see, for instance, discussions around employee boreout, for example, Stock, 2016), and too much support could turn into a demand if it irritates people which might be not uncommon in cultures with higher value on individualist aspects and autonomy (e.g. Limpanitgul et al., 2014). In the IBT context, another counterintuitive example is the duration of air travel. An overnight long-haul flight from Northern Europe to South Africa allowing for sleep and maintaining the circadian sleep-wake cycle (Wagner, 1996) could be seen as a resource, while a shorter flight from Northern to Southern Europe might require additional overnight accommodation and could be seen to establish a demand to IBTs.

The defining feature on whether a work characteristic is demanding or resourceful is likely therefore a result of the interaction with personal characteristics and in the case of IBTs, their travel patterns, suggesting a need for travel-specific categories and possibly additional considerations on processes and interaction effects. In JD-R theory, a demand or resource contributes to initiating a pathway, yet it may be that the work characteristics interact with personal characteristics (i.e. moderate or mediate) and that combination subsequently initiates a health impairment or motivational type process. Bakker and Demerouti (2017, p. 5) allude to this, highlighting that some "studies have shown direct links between variables involved in both processes (health impairment and motivational), which questions their independence" and "scholars may want to model the moderators of the job demands-resources relationship, and theoretically explain which type of effects can be expected". Furthermore, the point at which a work characteristic is perceived as low versus high (thus a demand or resource) likely differs between people and may change over time for each person. A multi-variate and curvilinear approach may also therefore be better for personal (e.g. psychological, physical, non-work or behavioural) and travel characteristics. The role of personal characteristics (i.e. psychological and physiological) in the health impairment and motivational processes has been highlighted as an existing shortcoming (Bakker and Demerouti, 2017).

Supporting this, a systematic review of JD-R literature to explore applicability across different national and international work contexts suggests possibility of a new interaction effect that's not accounted for in the existing literature base and a "robust international extension or adaptation of the JD-R model still has to be developed" (Rattrie and Kittler, 2014, p. 12). This review also suggests that international work brings demands and resources specific to IBTs (e.g. recovery time, quality of support in arranging travel, autonomy in travelrelated decisions and intensity of travel). Furthermore, a recent longitudinal study with 133 business travellers found frequent travel to either exacerbate or reduce both emotional exhaustion and engagement, depending on the level of work-life balance achieved and preventive coping strategies adopted (Niessen et al., 2018). This suggests that recovery and balance are important and these lifestyle factors are multi-variate - the combination of frequent travel, recovery and balance can cause ill-being (negative outcomes) or well-being (positive outcomes) depending on whether they are high or low and the work characteristic of frequent travel could conceptually present as either a job challenge or job hindrance or job resources, as opposed to, for example, pre-assigning it as a job hindrance that will remain static. 
Furthermore, cognitive flexibility (i.e. a psychological way of thinking that could be considered a personal resource) could be considered a personal resource that allows individuals to approach cultural differences and challenges faced on the road, with greater self-efficacy and flexibility. Cognitive flexibility in a general sense refers to "a person's (a) awareness that in any given situation there are options and alternatives available, (b) willingness to be flexible and adapt to the situation, and (c) self-efficacy in being flexible" (Martin and Rubin, 1995, p. 623). Specifically for international work, it refers to "the degree to which the global work requires role incumbents to adjust their thought patterns and scripts to effectively interact with people and adapt to situational demands" (Shaffer et al., 2012, p. 300). However, this psychological trait may not always present as a personal resource, for all employees, at all times and in some cases, could act as a personal challenge or hindrance. Acute stress (which is often present in IBTs) is thought to slow down cognitive flexibility, (Jiang and Rau, 2017) meaning they may struggle to adapt to new situations (that travel typically presents), lose perceived control over their abilities and be prone to negative thoughts and emotions (Gabrys et al., 2018).

\section{Methodology}

Qualitative designs are seen as powerful approaches in unravelling "rich and compelling insights into the real worlds, experiences, and perspectives" (such as those of IBT well-being) that might be "different to, but also sometimes complimentary to, the knowledge we can obtain through quantitative methods" (Braun and Clarke, 2014, p. 1). It is also known as a good way to capture complex experiences in a flexible manner (Merriam, 2009). Such an exploratory approach is therefore seen as appropriate for our research aims as the goal is to broaden understanding of a phenomenon not fully explained in extant literature with the subsequent intention to provide a framework for further quantitative studies to test propositions drawn from insights within this study. Our choice of method is also adopted elsewhere in IBT research with qualitative designs and thematic analyses not seen uncommon (e.g. Demel; Mayrhofer, 2010; Gustafson, 2014; Nicholas and McDowall, 2012).

Considering the theoretical contribution taxonomy presented by Colquitt and ZapataPhelan (2007), this work builds upon JD-R theory as a result of previously unexplored relationships or processes that, as according to Whetten (1989), add a novel "what" dimension to describe "how" processes unfold. This (intends to) alters current thinking on management of business travellers to avoid burnout and create engagement, therefore answering the "what's new?" question and shaping future thinking, emphasising novel changes to the theory that look to inform and impact the field.

\section{Participants}

A careful sampling approach, adhering to established benchmarks (see Robinson, 2013; Yardley et al., 2006), was used to enhance trustworthiness around sensitivity to context, rigour, transparency, coherence, impact and importance. Inclusion criteria are in line with the IBT definition provided earlier: individuals must travel internationally for work purposes for short periods (less than one month), without family members and reside in temporary accommodation. Our insights are based on interviews with 32 participants, nine of whom were female, with travel to Europe and the United States highly represented (see Table 1). The frequency of trips ranged from three times per year, to twenty-nine days per month, with duration two nights to twenty-nine consecutive days (see Table 1). All participants reported that they used flying as their dominant mode of transport.

Participants were recruited with maximum variation sampling, a successful method used in previous qualitative research to provide rich and detailed accounts (Makram et al., 2017).
Wellbeing of international business travellers 


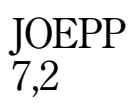

\begin{tabular}{|c|c|c|c|c|c|c|c|}
\hline ID & Gender & $\begin{array}{l}\text { Marital } \\
\text { status }\end{array}$ & $\begin{array}{l}\text { Country of } \\
\text { origin }\end{array}$ & $\begin{array}{l}\text { Country of } \\
\text { residence }\end{array}$ & $\begin{array}{l}\text { IBT } \\
\text { destinations }\end{array}$ & $\begin{array}{l}\text { IBT } \\
\text { frequency } \\
\text { (current) }\end{array}$ & $\begin{array}{l}\text { IBT } \\
\text { duration } \\
\text { (days) }\end{array}$ \\
\hline 01 & M & $\mathrm{Y}$ & UK & Switzerland & 1,2 & $1 /$ month & Various \\
\hline 02 & $\mathrm{~F}$ & $\mathrm{~N}$ & Romania & Switzerland & 1 & $2-3 /$ week & $1-2$ \\
\hline 03 & M & Y & Ireland & Switzerland & 1,2 & $2 /$ month & $5-7$ \\
\hline 04 & M & $\mathrm{Y}$ & Switzerland & Singapore & 1,4 & 4/year & $5-7$ \\
\hline 05 & M & $\mathrm{Y}$ & USA & Switzerland & 2 & Various & Various \\
\hline 06 & M & $\mathrm{Y}$ & Belgium & France & 7 & $1 /$ month & 2 \\
\hline 07 & $\mathrm{~F}$ & $\mathrm{Y}$ & Switzerland & Switzerland & 1 & 4-5/year & 2 \\
\hline 08 & M & $\mathrm{N}$ & USA & Switzerland & 1,2 & 3-4/year & $2-5$ \\
\hline 09 & M & $\mathrm{N}$ & South Africa & France & 7 & $\begin{array}{l}\text { Various ( } 50 \% \\
\text { of time) }\end{array}$ & $3-14$ \\
\hline 10 & M & $\mathrm{Y}$ & UK & Switzerland & $3,4,6$ & $1 /$ month & $14-30$ \\
\hline 11 & $\mathrm{~F}$ & $\mathrm{Y}$ & USA & Switzerland & 1 & 2/year & $3-4$ \\
\hline 12 & M & $\mathrm{N}$ & Switzerland & Singapore & 1,4 & $1 /$ two months & $7-14$ \\
\hline 13 & $\mathrm{~F}$ & $\mathrm{Y}$ & Switzerland & Switzerland & 4,5 & 3-4/year & 4 \\
\hline 14 & M & $\mathrm{Y}$ & UK & $\begin{array}{l}\text { Czech } \\
\text { Republic }\end{array}$ & 7 & $1 /$ month & 21 \\
\hline 15 & M & $\mathrm{Y}$ & USA & Switzerland & $1,2,4$ & $2 /$ month & $5-7$ \\
\hline 16 & M & $\mathrm{N}$ & UK & Switzerland & 1 & $1 /$ month & 3 \\
\hline 17 & $\mathrm{~F}$ & $\mathrm{Y}$ & Switzerland & USA & 1 & 3-4/year & $5-7$ \\
\hline 18 & M & $\mathrm{Y}$ & Switzerland & Singapore & 1 & $2 /$ month & Various \\
\hline 19 & M & $\mathrm{N}$ & UK & Switzerland & 1,2 & $1 /$ month & $14-21$ \\
\hline 20 & M & $\mathrm{N}$ & Switzerland & Monaco & 1,5 & $1 /$ month & $10-14$ \\
\hline 21 & $\mathrm{~F}$ & $\mathrm{~N}$ & Bahamas & Switzerland & 1,2 & $1 /$ month & $7-14$ \\
\hline 22 & M & $\mathrm{N}$ & Switzerland & Switzerland & 1 & $1 /$ month & 7 \\
\hline 23 & M & $\mathrm{Y}$ & Switzerland & Hong Kong & 1,4 & 3-4/year & Various \\
\hline 24 & $\mathrm{~F}$ & $\mathrm{Y}$ & Australia & Switzerland & 1,2 & $2 /$ month & $4-7$ \\
\hline 25 & M & $\mathrm{N}$ & USA & Switzerland & 7 & Various & Various \\
\hline 26 & M & $\mathrm{N}$ & UK & Switzerland & 7 & $1 /$ month & 29 \\
\hline 27 & M & $\mathrm{N}$ & India & India & 7 & 4-5/year & 14 \\
\hline 28 & M & $\mathrm{Y}$ & USA & Switzerland & 7 & 6-10/year & $1-7$ \\
\hline 29 & $\mathrm{~F}$ & $\mathrm{Y}$ & UK & France & 1,3 & 3-4/year & $5-7$ \\
\hline 30 & M & $\mathrm{N}$ & India & Switzerland & 1,2 & 4-5/year & 7 \\
\hline 31 & M & $\mathrm{Y}$ & UK & France & 1 & Various & Various \\
\hline 32 & $\mathrm{~F}$ & $\mathrm{~N}$ & France & Switzerland & 1,2 & 6/year & $2-5$ \\
\hline
\end{tabular}

Table 1.

Sample characteristics*
Note(s): Gender: $\mathrm{M}=$ Male; $\mathrm{F}=$ Female; Marital status: $\mathrm{Y}=$ Married; $\mathrm{N}=$ Not married; IBT destinations by region: 1 = Europe; $2=$ USA; $3=$ Africa; $4=$ Asia; $5=$ Middle East 6 = South America; 7 = Global operation; A number of participants were reluctant to share personal information and as such we are unable to report on further demographic data

International mobility networking websites were used, expected to capture a sample demonstrating patterns of business travel that would offer a realistic view and represent a relatively heterogeneous sample, built from largely work-contextual factors (Robinson, 2013). An intended sample of 30-40 was suggested, with data collection being monitored as research progressed as recommended by Silverman (2010), terminating when it was felt data saturation was reached and bounds of practical realities applied.

Given the exploratory in-depth nature with preferred focus on depth versus breadth, plus considering practicalities of our study context (Robinson, 2013), the sample size and characteristics were felt an appropriate range and sufficient to capture and control for different experiences and types of travel which is in line with previous qualitative research (e.g. Nicholas and McDowall, 2012; Sparrow, 2012). It also reflects Marshall et al. (2013), who 
report extreme variation in sample sizes for qualitative research, highlighting the mid-range (i.e. 20-40) as a good balance between devoting sufficient attention to reporting and analysing rich content on each interview, with achieving theoretical saturation.

\section{Interviews}

Semi-structured interviews were used, with exploratory and open-ended questions and prompts beginning with "why", "what" or "how" to encourage participant reflection and identify themes of significance whilst the researchers were careful to ensure sensitivity (Robinson, 2013). Interviews were transcribed verbatim and we used principles suggested by Francis et al. (2009) for determining data saturation in theory-based semi-structured interview studies using pre-established conceptual categories from existing theory.

Prior to the interviews, information was collected on trip frequency, duration and location. Participants were invited to discuss experiences of business travel, focussing on characteristics of work and the self that may be influential in development of positive or negative experiences. In order to classify data within the sea of syntax, units relating to conceptual themes developed in advance of interviews were identified and allocated. These units of syntax were examined in light of current literature to determine how well each unit related to a particular theme. The final themes were the result of an iterative process, where both researchers examined the transcripts multiple times. Data was also interpreted by identifying the frequency of words relating to particular themes, which further served to determine those most prominent.

\section{Analysis}

Thematic analysis was used to analyse data, chosen as it combines: flexibility for identifying themes; enables a detailed rich account that captures nuances, subtleties and depth; offers a robust, systematic framework for coding; and is a well-used approach particularly for health and well-being topics (Braun and Clarke, 2014). Analytic phases designed to enable emergent codes representative of important themes to surface, suggested by Braun and Clarke (2006), were followed, which included: familiarisation with data; generation of initial codes; searching for themes; reviewing, defining and naming themes; producing findings.

Initial codes were created, representing open-level coding whereby interesting pieces of information within raw data that might form the basis for repeated themes were extracted. During open-level coding, a broad approach was thought best to capture all potential codes, which were later refined against participant meaning and inconsistencies were addressed. At this point coding was data-driven to allow any predictive categories, direct or indirect effects that may influence the development of burnout to be identified.

Axial coding was then undertaken involving collating the open-coded data into potential themes, which represented a more manageable format. Care was taken to ensure a balance between depth and breadth at this point to achieve the right level of conceptual meaning. Lastly, selective coding was used to refine codes by reviewing themes, being careful to ensure they reflected the data set, were exhaustive, mutually exclusive and conceptually congruent (Merriam, 2009). When coding the researchers were careful to include surrounding text that reflected the context of a particular statement. Existing literature was consulted and researcher knowledge considered when naming themes and determining if they fell into a preexisting JD-R categories or represented a new category.

Resulting themes were considered with regard to experiences that are positive or negative, then themes mapped against JD-R categories of "challenges", "demands", "hindrances" and "resources" to identify the level of fit and additional themes representative of theory building, for example, a previously unexplored relationship, to understand "what" is happening and explain "how" a process unfolds. Using a deductive approach as one part of inductive
Wellbeing of international business travellers 
JOEPP
7,2

\section{6}

research is referred to as a small $q$ and is accepted to enhance qualitative methods (Braun and Clarke, 2014, p. 1). During the process, themes were reviewed by an additional researcher to discuss relationships and inconsistencies, discarding those that lacked evidence - a method adopted by previous researchers (e.g. Makram et al., 2017; Nicholas and McDowall, 2012). In doing so, semantic-level themes were identified using NVivo to reduce data into manageable forms with open, axial and selective coding, as recommended by (Miles and Huberman, 1994).

\section{Findings}

Context-specific processes and themes were identified, presented with associated syntax that illustrates antecedents of ill-being or well-being, pointing towards the requirement for theoretical specificity (see further). We suggest that JD-R theory does not fully capture the situation of individuals being deployed and travelling internationally, so we offer a revised model of IBT well-being that includes previously untested work and individual characteristics necessary for this context (see Figure 1).

\section{Context-specific processes}

It was apparent that trip load and intensity of travel were job characteristics unique to the IBT context. Through a JD-R lens these characteristics initially seem ambiguous and could be considered as hindrances, challenges or resources. Our interviews and analysis suggest that they are better placed on a multi-variate continuum of energy stimulation that may drive illbeing or well-being, conditional on the degree of presence versus absence (as opposed to preassigned categories).

There is no suggestion that trip load or even its constituents such as busy schedules are job hindrance demands and will always present in that pre-assigned category - as would be suggested by JD-R theory. Insights from our interviews do suggest that trip load could be either a job hindrance (i.e. requires effort that is health impairing) or challenge (i.e. requires effort, yet contains a motivational aspect due to assistance with learning and goal accomplishment) or resource (i.e. encouraging growth, learning, development, functional in achieving work goals and protecting against health impairment). There is potential to flow between these categories depending on the degree of presence or absence (i.e. suggesting a continuum) in the stimulation of positive or negative energy associated with well-being. The same principle would apply for intensity of travel.

Figure 1.

Energising international business travellers

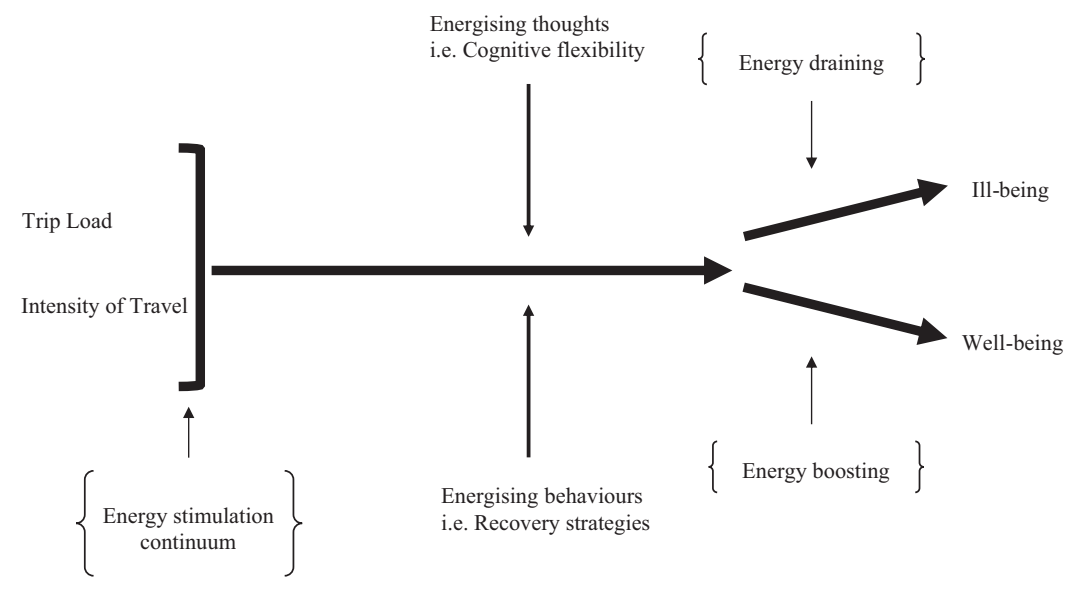


Cognitive flexibility and recovery behaviours are characteristics identified as critical for IBT well-being, representing something the individual holds or choices they can make (i.e. thinking styles and lifestyle behaviours) that moderate the relationship between job characteristics and well-being. Whilst cognitive flexibility fits with the JD-R lens of a personal resource, recovery behaviours indicate a new process, representative of strategic lifestyle behaviours an individual may craft as a method of self-managing the occupational conditions. It would appear that the "thinking" and "lifestyle behavior" processes operate in the same manner.

\section{Context-specific themes}

Trip load: Trip load was a job-characteristic-based theme that incorporated elements of workload and how that was managed - it appears that a greater load brings more energy draining (i.e. leading to burnout symptoms). Additional workload as a result of the trip, plus accumulation of regular responsibilities, was common amongst participants. Many were explicit regarding the stress that ensued, for example, reporting that "the week leading up to the trip and the week or two after I come back from a one-week long trip are typically a high stress time at work just because of all the preparation and all the follow-ups afterwards" (p. 31). In line with this, participants who experienced busy schedules whilst on a trip, usually from multiple meetings, tend to report symptoms of burnout: "It's always very stressful, because all the people want to see you during a very limited period of time. . . So I'm gonna have, let's say around 10 to 12 meetings in one day" (p. 04).

The perception of the trip load can be reduced by other elements of the job. Even if individuals were extremely busy whilst on their trips, organisational support in the form of effective processes and procedures (e.g. assistance with travel bookings, use of company credit cards, flexible booking policies) was reported to be well perceived. Similarly, with seamless travel and control over diaries, the energy draining consequences were not only reported to be mitigated but also over-ridden by a dialogue resonating with positivity and enthusiasm. A representative reflection of this observation is that "our company does a really good job in giving us those online tools to be able to do our research and figure out where we would find it most efficient and flexible to stay" (p. 27).

Intensity of travel: Intensity of travel, represented by frequency and duration of trips (associated with quality of travel discussed further), played another critical role in the IBTs' shared experiences. Participants reported that higher intensity of travel leads to exhaustion or stress and carries physical health consequences that are hard to revert - all symptoms and outcomes of ill-being. An example reflecting a job characteristic-energy draining/boosting relationship is a respondent who shares that "I was actually jet lagged for an entire month... I was tired and got quite sick. Erm, and so I was sick through all the trips and trying to power through. . . eventually I just had to take a day off work. . . And so I think you, you tend to ignore the physical needs. . . some rest and sleep" (p. 24). Here, the syntax highlighted how high intensity leads to health impairment.

Quality of travel, represented by standard of accommodation, flights and logistics, was frequently mentioned in travellers' reported experiences. Those who describe negative experiences refer to inability to change flights, restricted baggage, difficulty working during travel and lack of Internet to perform tasks, which worsen with a higher intensity of travel. Often, these conditions reflect consequences of budget restrictions, yet are felt to be cost-inefficient due to increasing exhaustion, increasing cynicism or efficacy in IBT effectiveness. For instance, "some of the company policies are difficult when I'm traveling so much, so we fly economy class only, with the lowest fare ticket ... if I'm doing a round the world trip in eight days it's all economy ... absolutely has an effect ... I absolutely can't sleep” (p. 10).
Wellbeing of international business travellers 
$\underset{7,2}{\text { JOEPP }}$

We also found that low intensity of travel actually generated positive energy boosting experiences, through respite from everyday stresses and routines. For instance, one respondent shared that "I always look forward to the meetings, I just happen to need to travel for those meetings, but the meetings themselves are always enticing and challenging in a positive way ... a break from the routine is something I quite look forward to. It's the top tier of my job satisfaction" (p. 24). Similarly, participants who received a higher quality of travel found the process enjoyable, relaxing and were in a position to be effective when it mattered most: "I work for a company that is realistic, when I take long trips I'm always on business class ... cost-conscious and restrictive in the handling of travel, can have a really negative impact not only on the business performance but the individual's desire to stay with that company. Makes it a positive experience" (p. 11).

\section{Thinking styles and lifestyle behaviours}

Cognitive flexibility played a prominent role, representing a key thinking style for IBT wellbeing and a potential moderator stemming from a personal characteristic. It would seem that IBTs' ability to be resilient in the face of pressure was determined by psychological thinking. In particular, the willingness of participants to be flexible and adaptable to situations as they emerge and confidently deal with them calmly to handle things in their stride - as Hemingway would say, "show courage under pressure" - was a prominent impression received from the interviews. For example, participants who reported energising experiences tended to look for options, be calm and make necessary adjustments with an automated self-awareness, for example, claiming "I'm very flexible. I find that I don't get worried about delays. I take things as they come. I adapt very quickly ... fairly patient and also accept that things are different in different places ... if we miss the plane, we miss the plane ... I thought there was nothing that I could do ... if there's nothing I can't control, I don't really stress about it” (p. 11).

Participants reporting of energising experiences also suggested to be very resourceful and adaptable to different contexts and gifted at making things work: "You always know things will work out one way or another ... even if things are not perfect, or rescheduled, or things, things are not, erm, you know, there's hiccups along the way. Whatever, you become very resourceful at being able to quickly make decisions" (p. 26). They tended to view new experiences, cultures and situations as positive, suggesting a way of thinking that bred success, for example, "having an open mind ... traveling does provide certain opportunities that are more driven by chaos and chance than by planned activity. You don't know you're sitting next to somebody in an airplane, you start a conversation. Some of the most important decisions I've made in my life, or insights that I've gained in my life, have come from that actually ... you're always looking out for, for new engagement, new interactions, new learning actually" (p. 26).

Recovery was considered essential in the overall experiences and consequences across our IBT sample, representing a lifestyle behaviour and appearing to act as a moderator or mediator between job characteristics and well-being. Participants who reported negative experiences and health impairment consequences described dealing with jet lag and lack of relaxation time as the two most prominent factors. The importance of looking after one's physical health and engaging in activities that involved accomplishment and provided meaning was recognised as being an important part of recovery, with some examples explicitly referring to the role of exercise. "Exercise and diet on the road do suffer ... it is not healthy, exercise thoroughly tends to suffer ... those are two things, which really do normally contribute to lower stress levels and better performance" (p. 23). We observed that participants who acquired adequate recovery reported positive experiences and health responses, achieving a better sense of lifestyle balance, psychological detachment and recharging, for instance, reporting that it is "quite nice to be able to sometimes have time in the plane for yourself and some time to think about things" (p. 06). 


\section{Discussion}

Scholars and practitioners appear to be facing the same problem with regard to IBTs (and also for a wider global mobility population): a persistent lack of clarity regarding contextsensitive antecedents of well-being. This research contributes to both theory and practice by indicating a modern landscape of previously less well presented or yet unidentified, contextspecific processes and themes that respond well to this dual problem, which are discussed further.

Regarding our first aim, due to the nature of frequent flying and associated lifestyle, our interview data illustrates that IBTs are prone to and at high risk of developing ill-being, yet at the same time, have potential to benefit from their international work environment and experience well-being if managed appropriately. It is therefore important to identify, understand and be in a position to manage those factors that matter most for IBT well-being, that is, those that should be prioritised in any intervention. We feel a contribution of this research is the identification of pertinent antecedents to IBT well-being, being trip load (i.e. workload, responsibilities, trip schedules, administration, travel bookings, flexible policies) and intensity of travel (i.e. frequency and duration of trips, quality of travel), plus individual characteristics representing psychological thinking styles (i.e. cognitive flexibility) and lifestyle behaviours (i.e. recovery strategies).

When we look to explain the antecedents outlined earlier, we find a degree of alignment to previous research. For example, adjustment to time zones, short notice of travel, changes in sleep patterns, additional workload and disruption to personal life (e.g. Mayerhofer et al., 2004; Striker et al., 1999; Welch et al., 2007) have all been identified as sources of work stress for IBTs. Likewise, the number of trips taken, frequency of trips and recovery time are previously shown to be prerequisites of exhaustion but also of vigour and performance (Demerouti et al., 2009; Sonnentag et al., 2012; Welch et al., 2007; Westman et al., 2008).

Regarding our second aim, job characteristics significant to the IBT context appear best placed on an energy stimulation continuum, activating energy draining or energy boosting pathways, leading to ill-being or well-being, respectively. The individuals' thinking and behaving appear to moderate this energy stimulation continuum and can be strategically crafted to self-manage well-being. Our insights therefore suggest a need for new constructs, relationships and processes specifically in well-being for IBTs, or from a broader lens, professionals who travel for work in global mobility (as opposed to an internationalised JD-R theory that applies to domestic and international work settings or alternative and earlier wellbeing theories applicable to general work contexts). We see this contribution as aligning to Colquitt and Zapata-Phelans' (2007) taxonomy, offering a theoretical contribution within the domain of "building new theory".

Our insights partially align with JD-R theory, agreeing in principal with the role of job demands and resources (i.e. intensity of travel, trip load) and personal resources (i.e. cognitive flexibility). However, JD-R theory emphasises that the objectivity of a work context assuming job characteristics can be categorised universally and exclusively, in an a priori manner for driving positive or negative outcomes. However, in our research, job characteristics are found to be either hindrances/challenges/resources depending on the degree of absence or presence, meaning any job characteristic holds potential to switch between energy stimulation states, causing ill-being or well-being in a multi-variate function.

It was also apparent that the mere absence of potentially energy draining job characteristics does not trigger energy boosts. For example, IBTs who reduce workload and frequency of trips (i.e. job characteristics held within high trip load or intensity of travel) may prevent ill-being by feeling less exhausted, yet this does not necessarily mean they will automatically feel more energised or achieve a higher level of well-being. Our findings also suggest that thinking style (cognitive flexibility) and lifestyle behaviours (recovery) are important issues serving as additional (or alternative) explanations. We view the latter as
Wellbeing of international business travellers 
JOEPP
7,2

more important because they could be seen to potentially act as valuable moderators, which the individual can self-manage and - in consequence - be empowered to "craft" well-being.

By definition of their jobs, IBTs need to travel and there can only be a certain amount of manipulation of job characteristics within those travel requirements. For instance, if their travel abroad would be fully replaced by virtual exchange, they would no longer be subject to our aforementioned definition submitting a substantial role of international business trips (Shaffer et al., 2012). While such a development might be beneficial to individuals' well-being and could be seen beneficial to organisational effectiveness, such a development lies beyond the scope of our study. Within the realm of IBTs, it might be recommendable to focus on ways to allow for developing energising thoughts and positive lifestyle behaviours. In our view, this represents a less explored opportunity and is something the employee can work on whilst on the road assuming they are equipped with adequate organisational support to do so. Given that participants indicated a lack of willingness to speak out about signs of ill-being, particularly in the early stages of burnout, providing support that helps them self-manage with the right skills, combined with a work environment conducive to openly speaking about any issues as they arise (in a preventative manner) could be very beneficial.

The inclusion of individual characteristics is in line with JD-R theory, which advocates the presence of personal resources to encourage competence, generate motivation and protect against health impairment. However, this requires consideration of two issues that our research has highlighted and that should be revisited. Firstly, a lack of consideration for what happens if desirable individual characteristics are simply not present. A lack of cognitive flexibility could diminish competence, remove motivation and trigger a health impairment process, therefore being detrimental to the IBT. Secondly, the very presence of cognitive flexibility could actually boost energy and well-being, not merely protect against health impairment. Our insights suggest the same principle applies for recovery, focussing on both behavioural choices and changes around, for example, nutrition, sleep, activity, lifestyle balance plus psychological recovery and activation of positive perceptions. Here, business and management literature might benefit from insights from professional sports research showing increased interest in such relationships (e.g. looking at international travel, sleep and recovery responses: Fullagar et al., 2016; Thornton et al., 2018).

\section{Implications for research and practice}

Our insights into the well-being of IBTs stimulate further research opportunities and our exploratory work raises issues that will benefit from further attention. Future research should focus on understanding the identified themes, their content, nature, role and influence on well-being along two streams. As our insights have highlighted the demanding complexities IBTs are exposed to in helping organisations respond to the volatility of the global business environment, a first stream of future research could look at the merits of new forms of international mobility and virtual assignments that might reduce the necessity of IBTs in the first place. Within the recent debate on travel, $\mathrm{CO}_{2}$ emissions and climate change are novel developments and insights that would certainly be desirable.

Assuming that international business travel will remain a prominent option used by international firms, a second stream of research should follow up potential responses from individuals and organisations (in single or multilevel designs) to shed further light on the nexus of this form of internationally mobile, its context and its work-related outcomes. Here, our study already provides some rich empirical insights that could be followed up or examined in more depth. For instance, future studies could aim to scrutinise preparation and recovery strategies, that is, focussing on aspects IBTs can practice before, during and after their travels, their outcomes and antecedents. Furthermore, here, identifying different traveller types might help organisations and HR practitioners in providing organisational 
support to, for example, develop identified antecedents in training programmes, enhancing IBTs' knowledge or skills development with tailored coaching. Better understanding working conditions, traveller types, travel characteristics and patterns could be beneficial to individual well-being and also to enhance international organisations' effectiveness.

Exploring the core logic behind the proposed model, testing each aspect and giving further insight into whether this represents a worthwhile extension to existing theory (or even yields novel theory) could be a next step. For example, identifying the "levels" of trip load or intensity of travel that activate energy draining or energy boosting processes would be insightful and how that interacts with the persons thinking and behaving along an energy continuum and would also remove current uncertainty regarding how, why or when they may drive energy and well-being. Likewise, exploring any job characteristics (non-travel related) that may be impacting these relationships, such as home-office work pressure or organisational support, could be beneficial to help design the workplace in a beneficial manner.

Through this process, confirming our findings in larger samples of IBTs, both quantitatively and longitudinally, would also enable our findings to be explained with greater certainty, findings to be generalised and bring confidence to academics and practitioners around causality. It may also deliver insight into the demographics, infographics and psychographics of IBTs, which is currently extremely scarce and beyond acknowledgement of its increased and increasing importance as outlined earlier also remains rather vague. Yes, there is an indication of the number of business trips taken per year, yet we do not know much more than that and certainly not to a degree that would allow comparison across research samples or robustly could guide practitioner decisions.

In addition to our recommendations for further research, implications to guide and inform practitioners emerge from our empirical insights. We submit that, particularly if enriched with findings from future research, our work could be seen as a starting point for of an effective path to manage job characteristics of IBTs. Additionally, our insights can provide practitioners with a sharpened focus for the benefits of training and development that directs self-management of well-being. It appears beneficial for organisations to monitor trip load and intensity of travel by working with the IBT, who can self-monitor to negotiate what will or will not work within the context of the travel destinations, the organisation and the individual IBT. Our study also highlights variation in the perception and role of job characteristics towards achieving well-being. For example, business travel can be initially exciting and rewarding, yet each person is likely to have a tipping point where the frequency, duration and quality become too much. Acknowledging the demanding element of job characteristics depending on their intensity, organisations can also reflect on monitoring their IBTs' well-being and develop potential interventions, with coaching and training to develop cognitive flexibility and improve choices and behaviours for recovery. This will likely create a sense of ownership, better lifestyle balance, bring flexibility and efficacy, which can protect against energy draining and drive energy boosts.

\section{Conclusion}

This qualitative study has a number of contributions, including identifying energy draining or energy boosting characteristics that drive ill-being or well-being for IBTs, and in doing so, proposes a new model incorporating pertinent job characteristics, thinking styles and lifestyle behaviours. Our insights identify the following as significant areas to focus on in the context of IBTs: job characteristics of trip load and intensity of travel; cognitive flexibility as psychological thinking characteristic; and recovery as behavioural choice. The novel lens presents a model whereby job characteristics operate on an energy stimulation continuum, driving energy draining or energy boosting pathways towards ill-being or well-being,
Wellbeing of international business travellers 

$\mathrm{JOEPP}_{7,2}$

respectively, moderated by psychological thinking and behavioural choices. These findings are a baseline for sharpening practical implications and future research directions.

\section{References}

Bakker, A.B. and Costa, P. (2014), "Chronic job burnout and daily functioning: a theoretical analysis", Burnout Research, Vol. 1, pp. 112-119.

Bakker, A.B. and Demerouti, E. (2017), "Job demands-resources theory: taking stock and looking forward", Journal of Occupational Health Psychology, Vol. 22, pp. 273-285.

Bakker, A.B., Schaufeli, W.B. and Sixma, H. (2000), "Patient demands, lack of reciprocity, and burnout: a five-year longitudinal study among general practitioners", Journal of Organizational Behavior, Vol. 21, pp. 425-441.

Bakker, A.B., Van Veldhoven, M.J.P.M. and Xanthopoulou, D. (2010), "Beyond the Demand-Control model: thriving on high job demands and resources", Journal of Personnel Psychology, Vol. 9, pp. 3-16.

Beaverstock, J.V., Derudder, B., Faulconbridge, J.R. and Witlox, F. (2009), "International business travel: some explorations", Human Geography, Vol. 91 No. 3, pp. 193-202.

Black, I. and Jamieson, S. (2007), "Up, up and fading away: the work and family life of executive international travellers", Policy and Practice in Health and Safety, Vol. 5 No. 2, pp. 63-78.

Boiler, C., Traber, Y. and Rattrie, L. (2017), Road to the Future: Anticipating Mobile Workforce Evolution, Health, Wealth, Career, Mercer.

Braun, V. and Clarke, V. (2006), "Using thematic analysis in psychology", Qualitative Research in Psychology, Vol. 3, pp. 77-101.

Braun, V. and Clarke, V. (2014), "What can "thematic analysis" offer health and well-being researchers?", International Journal of Qualitative Studies in Health and Well-being, Vol. 9, pp. 26-52.

Brookfield Global Relocation Services (2016), "Breakthrough to the future of global talent mobility", Global Mobilty Trends Survey, available at: http://globalmobilitytrends.bgrs.com/assets2016/ downloads/Full-Report-Brookfield-GRS-2016-Global-Mobility-Trends-Survey.pdf (accessed 26 July 2019).

Burkholder, J.D., Joines, R., Cunningham-Hill, M. (2010), "Health and well-being factors associated with international business travel”, Journal of Travel Medicine, Vol. 17, pp. 329-333.

Cardoso, A.R. and Jordão, F. (2017), "The Occupational stress in International Business Travellers of a multinational of the automotive sector", Revista Psicologia: Organizações e Trabalho, Vol. 17, pp. 235-242.

Cavanaugh, M.A., Boswell, W.R., Roehling, M.V. and Boudreau, J.W. (2000), "An empirical examination of self-reported work stress among U.S. managers", Journal of Applied Psychology, Vol. 85, pp. 65-74.

Cohen, S.A., Hanna, P. and Gössling, S. (2017), "The dark side of business travel: a media comments analysis", Transportation Research Part D: Transport and Environment.

Collings, D.G., Scullion, H. and Morley, M.J. (2007), "Changing patterns of global staffing in the multinational enterprise: challenges to the conventional expatriate assignment and emerging alternatives", Journal of World Business, Vol. 42, pp. 198-213.

Cohen, S.A. and Gössling, S. (2015), "A darker side of hypermobility”, Environment and Planning, Vol. 47, pp. 166-179.

Colquitt, J.A. and Zapata-Phelan, C.P. (2007), "Trends in theory building and theory testing: a fivedecade study of the Academy of Management Journal", Academy of Management Journal, Vol. 50, pp. 1281-1303. 
DeFrank, R.S., Konopaske, R. and Ivancevich, J.M. (2000), "Executive travel stress: perils of the road warrior", Academy of Management Executive, Vol. 14, pp. 58-71.

Demerouti, E., Bakker, A.B. and Bulters, A.J. (2004), "The loss spiral of work pressure, work-home interference and exhaustion: reciprocal re- lations in a three-wave study", Journal of Vocational Behavior, Vol. 64, pp. 131-149.

Demel, B. and Mayrhofer, W. (2010), "Frequent business travelers across Europe: career aspirations and implications", Thunderbird International Business Review, Vol. 52, pp. 301-311.

Demerouti, E., Bakker, A.B., Nachreiner, F. and Schaufeli, W.B. (2001), "The job demands-resources model of burnout", Journal of Applied Psychology, Vol. 86, pp. 499-512.

Demerouti, E., Bakker, A.B., Geurts, S.A. and Taris, T.W. (2009), "Daily recovery from work-related effort during non-work time", in Sonnentag, S., Perrewe, P.L. and Ganster, D.C. (Eds), Current Perspectives on Job-Stress Recovery: Research in Occupational Stress and Well-Being, JAI Press, Bingley, pp. 85-123.

Eyears, J. (2018), "Business travel, working abroad and mental health: a wake-up call", available at: https://www.personneltoday.com/hr/business-travel-and-mental-health-a-wake-up-call-foremployers/ (accessed 7 February 2019).

Francis, J., Johnston, M., Robertson, C., Glidewell, L., Entwistle, V., Eccles, M.P. and Grimshaw, J.M. (2009), "What is an adequate sample size? Operationalising data saturation for theory-based interview studies", Psychology and Health, Vol. 25, pp. 1229-1245.

Fullagar, H.H., Duffield, R., Skorski, S., White, D., Bloomfield, J., Kölling, S. and Meyer, T. (2016), "Sleep, travel, and recovery responses of national footballers during and after long-haul international air travel", International Journal of Sports Physiology and Performance, Vol. 11 No. 1, pp. 86-95.

Gabrys, R.L., Tabri, N., Anisman, H. and Matheson, K. (2018), "Cognitive control and flexibility in the context of stress and depressive symptoms: the cognitive control and flexibility questionnaire", Frontiers in Psychology, Vol. 9, pp. 1-19.

GBTA (2017), Creating a Frictionless Travel Experience. A Global Study on Business Traveller WellBeing, GBTA Foundation, available at: https:/hub.gbta.org/groups/reviews/item/20/11/2539.

Gill, R. (2016), “Ask the experts: why is traveller well-being important for your programme?”, available at: https://buyingbusinesstravel.com/feature/2825641-ask-experts-why-traveller-well-being-importantyour-programme, (accessed 7 February 2019).

Gustafson, P. (2014), "Business travel from the traveller's perspective: stress, stimulation and normalization”, Mobilities, Vol. 9, pp. 63-83.

Gustafson, P. (2016), "Work-related travel, gender and family obligations", Work, Employment and Society, Vol. 20, pp. 513-530.

Hakanen, J.J., Perhoniemi, R. and Toppinen-Tanner, S. (2008), "Positive gain spirals at work: from job resources to work engagement, personal initiative, and work-unit innovativeness", Journal of Vocational Behavior, Vol. 73, pp. 78-91.

Harrop, B. and Robertson, I. (2010), "Frequent traveller well-being. Its impact on the individual and the organisation", Icarus, pp. 1-11.

Hobfoll, S.E. (2001), "The influence of culture, community, and the nested-self in the stress process: advancing conservation of resources theory", Applied Psychology, Vol. 50, pp. 337-370.

Jensen, M.T. and Knudsen, K. (2017), "A two-wave cross-lagged study of business travel, work-family conflict, emotional exhaustion, and psychological health complaints", European Journal of Work and Organizational Psychology, Vol. 26, pp. 30-41.

Jiang, C. and Rau, P.L.P. (2017), "How acute stress alters cognitive flexibility function? The electrophysiological evidences", in The 2nd Asian Conference on Ergonomics and Design.

Karasek, R.A. (1979), "Job demands, job decision latitude, and mental strain: implications for job redesign", Administrative Science Quarterly, Vol. 24, pp. 285-308.
Wellbeing of international business travellers 

JOEPP
7,2

Limpanitgul, T., Boonchoo, P. and Photiyarach, S. (2014), "Coworker support and organisational commitment: a comparative study of Thai employees working in Thai and American airlines", Journal of Hospitality and Tourism Management, Vol. 21, pp. 100-107.

Mäkelä, L. and Kinnunen, U. (2018), "International business travelers' psychological well-being: the role of supportive HR practices", International Journal of Human Resource Management, Vol. 29, pp. 1285-1306.

Mäkelä, L., Bergbom, B., Tanskanen, J. and Kinnunen, U. (2014), "The relationship between international business travel and sleep problems via work-family conflict", Career Development International, Vol. 19, pp. 794-812.

Mäkelä, L., Saarenpää, K. and McNulty, Y. (2017), "International business travellers, short-term assignees and international commuters", Research Handbook of Expatriates, Vol. 15, pp. 276- 294.

Makram, H., Sparrow, P. and Greasley, K. (2017), "How do strategic actors think about the value of talent management? Moving from talent practice to the practice of talent", Journal of Organizational Effectiveness: People and Performance, Vol. 4, pp. 259-378.

Marshall, B., Cardon, P., Poddar, A. and Fontenot, R. (2013), "Does sample size matter in qualitative research?: a review of qualitative interviewing", The Journal of Computer Information Systems, Vol. 54, pp. 11-22.

Martin, M.M. and Rubin, R.A. (1995), "A new measure of Cognitive Flexibility”, Psychological Reports, Vol. 76, pp. 623-626.

Mayrhofer, W. Reichel, A. and Sparrow, P. (2012), "Alternative forms of international working”, in Shahl, G., Björkman, I. and Morris, S. (Ed.), Handbook of Research in International Human Resource Management, Elgar, Cheltenham, pp. 300-327.

Mayerhofer, H., Hartmann, L.C., Michelitsch-Riedl, G. and Kollinger, I. (2004), "Flexpatriate assignments: a neglected issue in global staffing", International Journal of Human Resource Management, Vol. 15, pp. 1371-1389.

McNulty, Y. and Brewster, C. (2017), "Theorizing the meaning(s) of 'expatriate': establishing boundary conditions for business expatriates", International Journal of Human Resource Management, Vol. 28 No. 1, pp. 27-61.

Merriam, S.B. (2009), Qualitative Research: A Guide to Design and Implementation, Jossey-Bass, San Francisco.

Meyskens, M., Von Glinow, M.A., Werther, W.B. Jr. and Clarke, L. (2009), "The paradox of international talent: alternative forms of international assignments", International Journal of Human Resource Management, Vol. 20, pp. 1439-1450.

Miles, M. and Huberman, A. (1994), Qualitative Data Analysis, Sage, California.

Miller, J. (2016), "The well-being and productivity link: a significant opportunity for research-intopractice", Journal of Organizational Effectiveness: People and Performance, Vol. 3, pp. 289-311.

Nicholas, H. and McDowall, A. (2012), "When work keeps us apart: a thematic analysis of the experience of business travellers", Community, Work and Family, Vol. 15, pp. 335-355.

Nielsen, K. and Miraglia, M. (2017), "What works for whom in which circumstances? On the need ot move beyond the 'what works?' question in organizational intervention research", Human Relations, Vol. 70, pp. 40-62.

Nielsen, K., Nielsen, M.B., Ogbonnaya, C., Kansala, M., Saari, E. and Isaksson, K. (2017), "Workplace resources to improve both employee well-being and performance: a systematic review and meta-analysis", Work and Stress, Vol. 31 No. 2, pp. 101-120.

Niessen, C., Müller, T., Hommerlhoff, S. and Westman, M. (2018), "The impact of preventive coping on business travelers' work and private life", Journal of Organizational Behaviour, Vol. 39, pp. 113-127. 
Podsakoff, N.P., LePine, J.A. and LePine, M.A. (2007), "Differential challenge stressor-hindrance stressor relationships with job attitudes, turnover intentions, turnover, and withdrawal behavior: a meta-analysis", Journal of Applied Psychology, Vol. 92, pp. 438-454.

Rattrie, L. (2017), "Business trips? Arrive with energy, perform when required and leave fully recharged", available at: https:/www.linkedin.com/pulse/business-trips-arrive-energy-performwhen-required-leave-rattrie/, (accessed 7 February 2019).

Rattrie, L. (2018), "Look at ways to manage your life before you suffer business burnout", available at: https://www.scotsman.com/news/opinion/lucy-rattrie-look-at-ways-to-manage-your-life-beforeyou-suffer-business-burnout-1-4750849, (accessed 7 February 2019).

Rattrie, L. and Kittler, M. (2014), "The job demands-resources model and the international work context - a systematic review", Journal of Global Mobility, Vol. 2, pp. 260-279.

Rattrie, L., Kittler, M. and Paul, K. (2019), "Culture, burnout and engagement: a meta-analysis on national cultural values as moderators in JD-R theory", Applied Psychology: An International Review, Vol. 69 No. 1, pp. 176-220.

Robinson, O.C. (2013), "Sampling in interview-based qualitative research: a theoretical and practical guide", Qualitative Research in Psychology, Vol. 11, pp. 25-41.

Rundle, A. (2018), "Just how bad is business travel for your health? Here's the data", available at: https://hbr.org/2018/05/just-how-bad-is-business-travel-for-your-health-heres-the-data, (accessed 7 February, 2019).

Rundle, A., Revenson, T.A. and Friedman, M. (2018), "Business travel and behavioral and mental health", Journal of Occupational and Environmental Medicine, Vol. 60, pp. 612-616.

Schaufeli, W.B. (2017), “Applying the job demands-resources model”, Organizational Dynamics, Vol. 46, pp. 120-132.

Shaffer, M.A., Kraimer, M.L., Chen, Y.-P. and Bolino, M.C. (2012), "Choices, challenges, and career consequences of global work experiences", Journal of Management, Vol. 38, pp. 1282-1327.

Siegrist, J. (1996), "Adverse health effects of high-effort/low-reward conditions", Journal of Occupational Health Psychology, Vol. 1, pp. 27-41.

Silverman, D. (2010), Doing Qualitative Research, Sage, London.

Sonnentag, S., Demerouti, E., Mojza, E.J. and Bakker, A.B. (2012), "Reciprocal relations between recovery and work engagement: the moderating role of job stressors", Journal of Applied Psychology, Vol. 97, pp. 842-853.

Sparrow, P. (2012), "Globalising the international mobility function: the role of emerging markets, flexibility and strategic delivery models", International Journal of Human Resource Management, Vol. 23, pp. 2404-2427.

Sparrow, P. and Cooper, C. (2014), "Organizational effectiveness, people and performance: new challenges, new research agendas", Journal of Organizational Effectiveness: People and Performance, Vol. 1, pp. 2-13.

Statista (2018a), "Forecasted number of domestic trips in the US", available at: https://www.statista. com/statistics/207103/forecasted-number-of-domestic-trips-in-the-us/, (accessed 26 July, 2019).

Statista (2018b), Global Business Travel Industry, available at: https://www.statista.com/topics/2439/ global-business-travel-industry/, (accessed 26 July 2019).

Stock, R.M. (2016), "Understanding the relationship between frontline employee boreout and customer orientation", Journal of Business Research, Vol. 69 No. 10, pp. 4259-4268.

Striker, S., Nagy, L., Liese, B., Bigelow, C. and Mundt, K.A. (1999), "Risk factors for psychological stress among international business travellers", Occupational Environmental Medicine, Vol. 56, pp. 245-252.

Tims, M., Bakker, A.B. and Derks, D. (2012), "Development and validation of the job crafting scale", Journal of Vocational Behavior, Vol. 80, pp. 173-186.
Wellbeing of international business travellers 

$\mathrm{JOEPP}_{7,2}$

Thornton, H.R., Miller, J., Taylor, L., Sargent, C., Lastella, M. and Fowler, P.M. (2018), "Impact of shortcompared to long-haul international travel on the sleep and wellbeing of national wheelchair basketball athletes", Journal of Sports Sciences, Vol. 36 No. 13, pp. 1476-1484.

Wagner, D.R. (1996), "Disorders of the circadian sleep-wake cycle", Neurologic Clinics, Vol. 14 No. 3, pp. 651-670.

Westman, M., Etzion, D. and Chen, S. (2009a), "Crossover of positive experiences from business travelers to their spouses", Journal of Managerial Psychology, Vol. 24, pp. 269-284.

Westman, M., Etzion, D. and Gattenio, E. (2008), "International business travels and the work-family interface: a longitudinal study", Journal of Occupational and Organizational Psychology, Vol. 81, pp. 459-480.

Westman, M., Bakker, A.B., van Emmerik, I.H., Etzion, D. and Chen, S. (2009b), "Crossover of positive experiences from business travelers to their spouses", Journal of Managerial Psychology, Vol. 24, pp. 269-284.

Welch, D.E. and Worm, V. (2006), "International business travellers: a challenge for IHRM", in Stahl, G. and Björkman, I. (Ed.), Handbook of Research in International Human Resource Management, Elgar, Cheltenham, pp. 283-301.

Welch, D.E., Welch, L.S. and Worm, V. (2007), "The international business traveller: a neglected but strategic human resource", International Journal of Human Resource Management, Vol. 18, pp. 173-183.

Whetten, D.A. (1989), "What constitutes a theoretical contribution?", Academy of Management Review, Vol. 14 No. 4, pp. 490-495.

Wright, T.A. and Cropanzano, R. (2000), "Psychological well-being and job satisfaction as predictors of job performance", Journal of Occupational Health Psychology, Vol. 5, pp. 84-94.

Wrzesniewski, A. and Dutton, J.E. (2001), "Crafting a job: revisioning employees as active crafters of their work", Academy of Management Review, Vol. 26, pp. 179-201.

Xanthopoulou, D., Bakker, A.B., Demerouti, E. and Schaufeli, W.B. (2009), "Reciprocal relationships between job resources, personal resources, and work engagement", Journal of Vocational Behavior, Vol. 74, pp. 235-244.

Xanthopoulou, D., Bakker, A.B., Dollard, M.F., Demerouti, E., Schaufeli, W.B., Taris, T.W. and Schreurs, P.J.G. (2007), "When do job demands particularly predict burnout? The moderating role of job resources", Journal of Managerial Psychology, Vol. 22, pp. 766-786.

Yardley, A.K., Ortega, A.N. and Kumanyika, S.K. (2006), "Effective recruitment and retention of minority research participants”, Annual Review of Public Health, Vol. 27, pp. 1-28.

\section{Further reading}

Association U.S.T. (2009), "The return on investment of U.S. business travel", available at: https:// www.oxfordeconomics.com/Media/Default/Industry $\% 20$ verticals/Tourism/US $\% 20$ Travel $\%$ 20Association-\%20ROI\%20on\%20US\%20Business \% 20Travel.pdf, (accessed 26 July 2019).

Bakker, A.B. and Demerouti, E. (2014), "Job demands-resources theory”, in Chen, P.Y. and Cooper, C. (Ed.), Well-being: A Complete Reference Guide, John Wiley \& Sons, pp. 1-29.

Bryson, A., Forth, J. and Stokes, L. (2017), "Does employees' subjective well-being affect workplace performance?”, Human Relations, Vol. 70, pp. 1017-1037.

Crawford, E.R., LePine, J.A. and Rich, B.L. (2010), "Linking job demands and resources to employee engagement and burnout: a theoretical extension and meta-analytic test", Journal of Applied Psychology, Vol. 95, pp. 834-848.

Drummond, S., O’Driscoll, M.P., Brough, P., Kalliath, T., Siu, O.-L., Timms, C., Riley, D., Sit, C. and Lo, D. (2017), "The relationship of social support with well-being outcomes via work-family conflict: moderating effects of gender, dependants and nationality", Human Relations, Vol. 70, pp. 544-565. 
Grote, G. and Guest, D. (2017), “The case for reinvigorating quality of working life research", Human Relations, Vol. 70, pp. 149-167.

Kittler, M. (2018), "Do we understand each other? Discussing academic exchange from a cross-cultural communication perspective", International Studies of Management and Organization, Vol. 48 No. 3, pp. 156-186.

Nahrgang, J.D., Morgeson, F.P. and Hofmann, D.A. (2011), "Safety at work: a meta-analytic investigation of the link between job demands, job resources, burnout, engagement, and safety outcomes", Journal of Applied Psychology, Vol. 96, pp. 71-94.

Oddou, G., Mendenhall, M.E. and Ritchie, J.B. (2000), "Leveraging travel as a tool for global leadership development”, Human Resource Management, Vol. 39, pp. 159-172.

\section{Corresponding author}

Lucy Rattrie can be contacted at: lucy@creatingsona.com
Wellbeing of international business travellers

For instructions on how to order reprints of this article, please visit our website:

www.emeraldgrouppublishing.com/licensing/reprints.htm

Or contact us for further details: permissions@emeraldinsight.com 